\title{
Cross-Cultural Communication Simulation Game: Lessons for Educators
}

\author{
Ghadah Al Murshidi, Mohamed Al Memmari, Ahmed Al Zaabi, Mohamed Al Zaabi
}

UAEU

\begin{abstract}
.
Barnga intercultural simulation is used in international education as an activity to prepare students for a study abroad experience. We attempted to assess the usefulness of adapting Barnga intercultural simulations in Omani institutions. The aim of my study is to research the perceived benefit of adapting 'Barnga' intercultural simulation in Omani institutions. It is a card game simulation which target to help participants to develop their intercultural competence. It is the first time to do this simulation and to study it in the Omani context. Therefore, we research this topic to, hopefully, provide some evidence for the usefulness and success of adapting Barnga in Omani institutions. Then I may be able to propose it to be done for three types of groups who participate in this study. The research participant groups are: Omani students traveling abroad to study, Omani university students studying in Oman and lecturers at Omani universities/colleges. We used a questionnaire for the two students groups to examine their perceptions after they participate in the Barnga simulation. I designed the questions to work on Bennett's (1993) frame of intercultural development. The questions have been phrased in simple words, but in a way to measure how successful were the participants on each of Bennett's scale stages. The lecturers group will be requested to participate in the Barnga simulation and data will be collected through a focus group interview. The findings of this study are analysed and discussed to reveal the perceived benefits of Adapting Barnga simulation in each of the groups.
\end{abstract}

Keywords: Intercultural interaction, Omani institutions, tolerance, Adaptation, different groups 